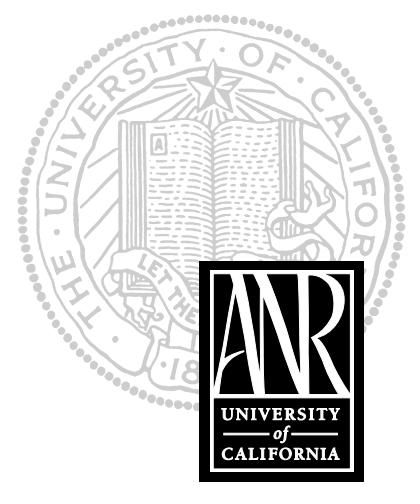

UNIVERSITY OF CALIFORNIA

Division of Agriculture and Natural Resources

http://anrcatalog.ucdavis.edu
PUBLICATION 8015

\section{Guidelines for Controlling} Listeria monocytogenes in Small- to Medium-Scale Packing and Fresh-Cut Operations

TREVOR SUSLOW, Extension Specialist, University of California, Davis; and LINDA HARRIS, Extension Specialist UC Davis. The assistance of Shantana George is gratefully acknowledged.

- ecent outbreaks of the bacterial pathogen Listeria monocytogenes have drawn Mattention to the severity of listeriosis in humans, and to the risk of L. monocytogenes contamination in all foods. The risk is highest in refrigerated and ready-to-eat foods because L. monocytogenes is one of the few foodborne pathogens capable of multiplying at refrigerated temperatures. New handling and packaging technologies that extend visual quality of fresh produce items and inhibit normal spoilage organisms may result in the consumption of a food beyond its generally recognized safety period. Healthy individuals are not usually affected when they consume foods containing this organism. However, illness can be very severe in immune-compromised individuals and in pregnant women. Mortality rates of 20 to 30 percent are not uncommon in listeriosis cases. Listeria monocytogenes is found almost everywhere and can be readily isolated from most environments, including soil, humans, animals, agricultural irrigation sources, decaying plant residue on equipment or bins, cull piles, packing sheds, and fresh-cut processing systems. The widespread nature of L. monocytogenes mandates a systematic approach to sanitation of high-risk locations in packing operations. Although the clinically demonstrated linkage between listeriosis and fresh fruits and vegetables is very limited, the risk is serious and appears to be increasing. A consistent monitoring system, especially for fresh-cut produce processors, is strongly recommended. The severity of listeriosis to humans demands immediate corrective action when L. monocytogenes is detected in a packing or fresh-cut processing facility.

Unfortunately, the fact that L. monocytogenes is present in most environments renders it nearly impossible to eliminate completely from a packing shed. This bacterium is constantly being reintroduced into the plant by employees and by incoming products, soil, vegetation, and equipment. Monitoring for general cleanliness and sanitation with respect to overall microbial populations is always important, but the unique ability of Listeria to persist and multiply on equipment, in the packing shed, and in a fresh-cut plant environment demands special attention. Produce buyers are increasingly expecting growers and shippers of all scales to verify that they have a Listeria management program in their operational plan.

U.S. regulatory agencies consider L. monocytogenes an adulterant in ready-to-eat foods, and as such, they will ask a company to recall a product found to be contaminated with this bacterial pathogen. The policy, known as "Zero Tolerance," is one reason why L. monocytogenes control should be a primary concern with packers and shippers. 
Control of L. monocytogenes in a plant requires reducing the number of these bacteria on products and equipment surfaces via physical means and preventing general growth and proliferation of Listeria, by managing the environment. Cleaning and sanitizing treatments applied to equipment, walls, and drains should be adequate to destroy or remove L. monocytogenes. Guidelines vary since adequate treatment depends on the equipment and environment in each plant. This document will primarily address the second element of control: preventing establishment and proliferation of Listeria in the packing and processing environment. This aspect involves regular sanitation of equipment surfaces and consistent monitoring of these surfaces. In order to verify control of L. monocytogenes, managers should, at minimum, implement a short-term monitoring program that tests for indicator bacteria, such as "generic Listeria" to establish a baseline of performance in general sanitation procedures. This monitoring program acts to detect the presence of all Listeria species, with the assumption that if any Listeria species are detected, L. monocytogenes may also be present. The program becomes plant-specific when the frequency of sampling, location of samples, and the corrective action taken are tailored to the plant's operation. Each product and process within each facility should be considered a separate unit, and appropriate monitoring points should be developed according to this philosophy.

The goal of this publication is to offer guidelines for monitoring and minimizing the presence of L. monocytogenes in an agricultural packing operation and minimizing the possibility of its presence in the final food product, whether sold as a raw agricultural product or uncooked minimally processed vegetable.

\section{GENERAL CONSIDERATIONS}

A product is most likely to become contaminated when it comes into contact with a contaminated surface. This risk is highest between the primary trimming or chopping step and the packaging step. This is because various processing measures may occur after cutting, with no effective treatment to clean the product before packaging. Common sites for this type of cross-contamination are listed below:

- Slicers, dicers, shredders, and blenders used after cutting and trimming but before packaging

- Conveyors

- Holding containers such as bins, tubs, or baskets used for spin-drying or to hold the finished product before packaging or further processing

- Solutions used to chill product

- Hand tools, gloves, and aprons that come into contact with finished product

- Racks for transporting before packaging

- Collators used to assemble and arrange product before packaging

- Filling or packaging equipment

\section{S A M P LIN G}

Weekly sampling is recommended for most wet areas since these are the areas most attractive to bacteria. Drains, floors, walls, and overhead and support structures are recommended for sampling. Air sampling may be advisable in some operations. After a profile of potential bacteria-harboring sites is established, the plant should develop its sampling schedule accordingly. Any increased incidence in the presence 
of generic Listeria should be further investigated. If a sample that is positive for generic Listeria is a composite sample, the individual samples that made up the composite should be retested to determine where the contamination is occurring.

Remember that any contamination during processing will continue to spread downstream. If further sampling of a positive site is positive, use of that site and all sites downstream from it should be suspended. Intensive cleaning and retesting of the site should be completed. All positives that occur on food contact surfaces should be investigated. Determine which remedial actions are appropriate, including modification of cleaning and sanitizing procedures, equipment redesign, retraining, and so on.

Product sampling (final packed or minimally processed and packaged produce) to test for L. monocytogenes remains a controversial point in food safety management and is of debatable value. Initial levels of Listeria in the product are likely to be very low and not uniformly distributed. Therefore, the effectiveness of monitoring to provide safety assurance is questionable. Statistically, unless the final product is grossly contaminated, it is highly unlikely that a practical and economical random sample of finished product would result in a positive detection. Monitoring retained product held under refrigeration for an extended period has been more reliable in detecting L. monocytogenes on diverse leafy vegetables. Unfortunately, this information is limited and largely of retrospective value only.

If the food contact surface sampling result is positive, the product must be held or recalled until confirmatory lab results are obtained.

In-house testing for L. monocytogenes is only recommended when appropriate facilities are available for the testing. In addition, adequately trained microbiologists should perform the testing procedures. Many of the test procedures function by steps that amplify the levels of L. monocytogenes, if it is present, which requires absolute containment and consistent, good laboratory practices to prevent accidental transfer to outside the lab area. Poorly trained individuals or inappropriate facilities could lead to further contamination of the processing facility.

There are many commercial testing facilities that can safely perform these tests. (See Additional Resources.)

\section{POSTHARVEST OPERATIONS}

A safe general rule is to assume that any breakdown or change made to a facility or packing line might introduce or cause contamination of the packing shed or freshcut plant. Examples include the following:

- Postharvest wash water comes from a new, possibly contaminated source.

- A packaging line is moved or changed.

- Used equipment is brought in and installed without thorough cleaning and sanitation.

- Equipment breakdown leading to the ineffectiveness of some of the barriers to bacterial contamination.

- A drain back-up.

- Product gets caught in newly installed or modified equipment, allowing time for microbial growth in the system.

- Construction in the ready-to-eat product area.

- A new employee is not familiar with the safeguards against L. monocytogenes contamination. 
Periods of heavy production can lead to a special group of problems. In this case, elimination of the scenarios listed below is essential to controlling the growth and spread of L. monocytogenes:

- Personnel are moved from the field or receiving dock to the finished product area, leading to cross-contamination.

- Busy periods of packaging make it difficult to clean and sanitize as often as necessary.

- Inadequately cleaned product or postharvest equipment in the finished product area.

- Frequent product changeovers.

Some basic packinghouse management guidelines can significantly limit the possibility of L. monocytogenes contamination:

- Remove plant residue and rinse plant liquids from harvest and packing surfaces, belts and conveyors, bins, and totes.

- Make sure that equipment, parts, and product bins and totes are not cleaned on bare soil or on the floor, where L. monocytogenes contamination is most common.

- Waste or cull bins in final packing areas should be in good repair, cleaned, and sanitized.

- Traffic flow between receiving, packing, and shipping areas should be controlled. This includes maintenance employees and outside contractors and their tools, in addition to traffic between raw and ready-to-eat agricultural product areas.

- Product flow should proceed in a linear fashion to avoid contact between field products and final packed products.

- It may be beneficial to establish positive air pressure in the finished product area (relative to the raw material side) to contain contamination.

- Compartmentalize. Dedicate separate washing areas for field equipment, colorcode trash barrels according to field or final product, use separate utensils, and so on.

- Wet process areas should be separated from other areas whenever possible. Bacteria require a cool, damp place to grow, and limiting the amount of standing water helps control the growth of L. monocytogenes and most other bacteria.

- Drains from the "soiled" side of packing or processing should not be connected to the drains from the "clean" side.

- Eliminate overhead fixtures in the finished product area wherever possible, especially over areas where the ready-to-eat product is exposed.

- Footbaths can be installed but should be maintained properly. The maintenance of clean, dry floors is more effective. The use of chlorine in a footbath is not recommended because it quickly becomes deactivated. An iodophor or quaternary ammonium compound is preferred.

- Water that comes into contact with product should contain an antimicrobial agent effective against L. monocytogenes. 


\section{PACKAGING AND STORAGE}

- Pallets entering the packaging room should be clean and dry. It is much easier to transfer bacteria between wet surfaces.

- Packing materials should be palletized and covered until used.

- Cooling units should have dehumidifying properties in order to limit moisture in these areas.

\section{EQU IP MEN T}

Other areas in the plant can provide a place for Listeria to grow and contaminate the product indirectly:

- Equipment framework (especially rotating blades, belts, etc.)

- Floors

- Drains

- Walls, especially cracks that retain moisture

- Ceilings, catwalks

- Condensate

- Wet insulation

- Trolleys, forklifts, walk-alongs

- Cleaning tools such as sponges and brushes

- Maintenance tools

Equipment is often forgotten in the scheme of minimizing L. monocytogenes risk, but it provides numerous hiding places for bacteria. The following considerations decrease the risk of L. monocytogenes contamination of equipment contact surfaces and product surfaces:

- All equipment should be designed to be easily cleaned and serviced.

- Previously-used equipment must be thoroughly cleaned and sanitized. Disassemble equipment to clean as needed.

- Maintain equipment in order to minimize breakdowns because the repair of equipment provides an opportunity for the introduction of contamination.

- Hollow equipment or catwalk frames should be prohibited.

- Lubricants should contain a listericidal additive, like sodium benzoate, to prevent them from becoming a harboring point for L. monocytogenes.

- Conveyors should not contain hollow rollers and should not be located near the floor. In addition, overhead conveyors should be avoided because they are harder to clean and inspect.

- Transporting racks should have cover guards over the wheels to prevent spray from the wheels from reaching the product.

- If compressed air is used to remove debris from equipment, be sure to maintain and replace in-line filters regularly.

- Coolers or other rooms should not be cleaned when ready-to-eat food is exposed. 


\section{SAN ITATION}

Follow a standard cleaning procedure:

- Dry clean.

- Prerinse equipment.

- Visually inspect equipment.

- Foam and scrub equipment.

- Rinse equipment.

- Visually inspect equipment.

- Clean floors.

- Sanitize equipment and floors.

- Conduct postsanitation verification.

- Dry floors.

- Clean and put away supplies. Some plants use the following sanitizing protocol:

- After cleaning equipment, apply a high level of chemical sanitizer (800 ppm quat) and let it sit for 20 minutes.

- Rinse, and then apply a normal level of sanitizer (200 ppm).

- At the end of the week, apply a high level of sanitizer and leave it on equipment until just before start-up.

- Rinse high level of sanitizer and apply a normal level. Then rinse off at start-up.

- It may be beneficial to spray 200 ppm quat aerosol into a room as final sanitation step, weekly or monthly.

- The most reliable method of sanitizing equipment is with heat. Heat may be applied using hot water $\left(180^{\circ} \mathrm{F}\right.$ rinse), steam, or the application of moist heat in an oven to raise the temperature to $160^{\circ} \mathrm{F}$ or higher.

- When using heat to sanitize, it is very important that all soil is removed from the apparatus so that it does not bake on.

- Chemical sanitizers such as iodophor (200 ppm) and quaternary ammonium compound (400-800 ppm) are effective on equipment and other surfaces. Sanitizers containing peracetic acid and peroctanoic acid are also effective against L. monocytogenes. Chlorine may be used, but as with foot baths, the chlorine quickly becomes deactivated.

- Rotating sanitizers in the program may increase effectiveness.

- Sanitizing with high temperatures may increase effectiveness. See the manufacturers' instructions to judge whether this is advisable with the product.

Table. Areas to clean with quats or peracid

\begin{tabular}{ll}
\hline Area & Frequency \\
\hline Drains & daily \\
Floors & daily \\
Waste and storage containers & daily \\
Walls & weekly or monthly \\
Condense drip pans & weekly or monthly \\
HVAC & weekly or monthly \\
Coolers & weekly or montly \\
\hline
\end{tabular}




\section{GENERAL PLANT SANITATION}

- Visual inspection and routine microbiological testing (for example, Aerobic Plate Count) are important in the development of an idea of what potential bacterial problems are present in a plant. Commercial bioluminescent monitoring systems are useful in observing overall sanitation. However, none of these techniques are specific for L. monocytogenes. A generic Listeria monitoring system is also recommended.

- Clean-up crews should receive special training in controlling L. monocytogenes, as well as close supervision. The clean-up crew is most effective if employees understand why sanitizing procedures are necessary. Management and employees should share the view that monitoring is needed to identify needs and opportunities to improve cleaning techniques or frequency in specific areas.

- Midshift cleanups should be eliminated when possible, as they produce aerosols and add water to the processing environment.

- A hose emptying in a drain should divert condensate from drip pans of refrigeration units. Solid sanitizers should be placed in the drip pans.

- Use a caustic cleaner to clean floors. Use brushes that are color-coded according to what processing area they belong to.

- Make sure drains are designed to prevent backups. Stop production if a backup does occur. The room must then be cleaned, rinsed, and sanitized. Do not clear a drain with a high-pressure hose, as this creates an aerosol throughout the room.

- Eliminate trench drains where possible.

- Use bactericidal drain rings.

- Brushes used for cleaning drains should be dedicated to that purpose.

- Sanitize cleaning tools with 600 to 1000 ppm quaternary ammonium solution.

\section{EMPLOYEE HYGIENE}

- Clean gloves, smocks, and aprons are essential. Depending on your operation, color-code these items according to which production area the employee is assigned.

- Make sure employees understand that the clean garments and disposable gloves are to protect the product from contamination, not to protect the employees from getting dirty.

- If an employee touches an unclean surface, their hands should be washed and their gloves changed.

- If possible, have one person in the packaging room responsible solely for picking up material from the floor, removing trash, and so on.

\section{CONCLUSION}

The most important point in limiting risk for L. monocytogenes contamination may be in ensuring that personnel are aware of the severity of the effects of contamination and what practices increase this risk. Many seemingly insignificant practices, such as setting equipment on the floor to clean it, not wearing clean gloves, or handling "dirty" produce or equipment and then touching cut and trimmed or packed produce, can be catastrophic for a processing system. Make sure that every employee feels a sense of personal responsibility toward maintaining the sanitation and safety of the plant. 


\section{ADDITIONAL RESOURCES}

The following USDA site has links to current information on L. monocytogenes. Much of the information for the food industry is related to ready-to-eat meats. However, the means to control L. monocytogenes is very similar for all food types.

http://www.fsis.usda.gov/OA/topics/lm.htm

The following site provides very detailed information regarding L. monocytogenes and testing and detection procedures.

http://seafood.ucdavis.edu/HACCP/Compendium/Chapt15.htm

A list of commercial food testing laboratories (primarily in California) can be found at the following site.

http://foodsafe.ucdavis.edu/ResourceGuide

\section{FOR MORE INFORMATION}

You'll find detailed information on many aspects of postharvest handling and food safety in these UC ANR publications:

Commercial Cooling of Fruits, Vegetables, and Flowers, publication 21567

Postharvest Technology of Horticultural Crops-Second Edition, publication 3311

Don't Give Kids a Tummyache (CD ROM), publication 21586

To order these materials, visit our online catalog at http://anrcatalog.ucdavis.edu. You can also place orders by mail, phone, or fax, or request a printed catalog of publications, multimedia, slide sets, and videos from

University of California

Division of Agriculture and Natural Resources

Communication Services

6701 San Pablo Avenue, 2nd Floor

Oakland, California 94608-1239

Telephone: 1-800-994-8849 or (510) 642-2431, FAX: (510) 643-5470

e-mail inquiries: danrcs@ucdavis.edu

An electronic version of this publication is available on the ANR Communication Services website at http://anrcatalog.ucdavis.edu.

Publication 8015

(C) 2000 by the Regents of the University of California,

Division of Agriculture and Natural Resources. All rights reserved.

The University of California prohibits discrimination against or harassment of any person employed by or seeking employment with the University on the basis of race, color, national origin, religion, sex, physical or mental disability, medical condition (cancer-related or genetic characteristics), ancestry, marital status, age, sexual orientation, citizenship, or status as a covered veteran (special disabled veteran, Vietnam-era veteran or any other veteran who served on active duty during a war or in a campaign or expedition for which a campaign badge has been authorized).

University Policy is intended to be consistent with the provisions of applicable State and Federal laws. Inquiries regarding the University's nondiscrimination policies may be directed to the Affirmative Action/Staff Personnel Services Director, University of California, Agriculture and Natural Resources, 1111 Franklin, 6th Floor, Oakland, CA 94607-5200 (510) 987-0096. 